\title{
MODELING OF DISCONTINUOUS DEFORMATIONS OVER SHALLOW POST - MINING VOIDS IN THE ROCK MASS
}

\author{
Wieslaw PIWOWARSKI ${ }^{1)}$ and Piotr STRZAŁKOWSKI ${ }^{2)}$ * \\ 1) AGH University of Science and Technology, ul. Mickiewicza 30, 30-059 Krakow, Poland \\ ${ }^{2)}$ Silesian University of Technology, ul. Akademicka 2a, 44-100 Gliwice, Poland \\ *Corresponding author's e-mail: piotr.strzalkowski@polsl.pl
}

\begin{tabular}{|c|c|}
\hline ARTICLE INFO & ABSTRACT \\
\hline Article history: & \multirow{6}{*}{$\begin{array}{l}\text { Sinkholes that are often formed over shallow mining workings constitute a significant threat to } \\
\text { buildings, infrastructure and - most of all - to the residents. These deformations often occur after } \\
\text { a long time following the completion of mining works. A considerable number of sinkholes are } \\
\text { formed above shallow headings due to the loss of bearing capacity of old wooden supports. } \\
\text { Because of the above, the problem of predicting the formation of sinkholes gains significance. } \\
\text { This paper presents the assumptions of Strzałkowski's method of predicting discontinuous } \\
\text { surface deformations (sinkholes). The deterministic model reflects the essence of the mechanism } \\
\text { of destruction of the rock mass surrounding the void. The presented study case - another } \\
\text { example of using the method for providing an ex post prognosis indicates its practical usability. } \\
\text { The computer programme used in this paper is helpful to laborious calculations. }\end{array}$} \\
\hline Received 23 January 2019 & \\
\hline Accepted 23 May 2019 & \\
\hline Available online 20 August 2019 & \\
\hline Keywords: & \\
\hline $\begin{array}{l}\text { Sinkhole } \\
\text { Post-mining deformations }\end{array}$ & \\
\hline
\end{tabular}

\section{INTRODUCTION}

The environmental impact of mining activity encompasses a wide variety of factors. Among other things, the negative effects of mining activity include, as noted by Strzałkowski (2010):

- continuous deformations of the rock mass,

- discontinuous deformations: surface (mostly sinkholes), linear (predominantly steps),

- changes in groundwater conditions (overflow lands), water pollution,

- transformations of landscape and natural relief.

In the Upper Silesian Coal Basin, coal exploitation has continued for over 200 years. Thus, it does not come as a surprise that changes in the natural environment, including vast and irreversible deformations of landscape, have resulted from this exploitation.

The discontinuous deformations hazard is particularly present in the areas of former shallow exploitation of different useful minerals, for example of hard coal and ores of metals in Poland and gypsum in the Ebro Basin in Spain described in the article written by Soriano et. al. (1994), in US (Hunter, 2015), Germany (Kratzsch,1983), UK (Redish and Whittaker, 1989) and many other countries.

Discontinuous deformation processes described by Dżegniuk et al. (1994) occur rapidly, are extremely harmful and proceed irregularly, causing damages to buildings, industrial structures, communication infrastructure, etc. Due to the above, as noted by Kaufmann (2014), the performance of geophysical tests before initiating an investment is necessary in areas where mining works were formerly conducted at low depths.
Sinkhole processes cause characteristic surface deformations, that is, the loss of integrity of geological layers leading to local discontinuous subsidences of the surface area. The basic characteristics of sinkholes include: apparent randomness, sudden changes in the system dynamics. The formation of sinkholes in mining areas depends on a series of factors. In the paper (Malinowska and Matonóg, 2017) these include: the depth of the void, the density of the underground headings network, the thickness of the loose overburden, the overlapping edges of exploitation in horizontal projection, the height of the secondary void, the presence of mine shafts, the traffic of vehicles causing vibrations.

One should also note that the formation of sinkholes may be related to natural causes. These may include the loss of stability of shallow voids which have formed due to karst phenomena or due to suffusion (Xiao et al., 2016). Karst phenomena are a cause of numerous sinkholes in Florida (Doctor et al., 2008), causing extraordinary hazards in highly urbanized areas (Brinkmann et al., 2008).

In such cases it is significant to assess the postmining hazards by means of a procedure - to determine the field of peculiar displacements (in mathematical sense) of a given part of the rock mass and the probability of sinkhole formation. Both the possibility of formation of natural sinkholes - as exemplified by Baryakh and Fedoseev (2011), and the sinkholes of anthropogenic origin are predicted with usage of methods described by Chudek et el. (1988). In the paper by Baryakh and Fedoseev (2011), referred to above, the range of plastic deformations around a karst cavern was determined by numerical methods, and subsequently a condition of sinkhole 


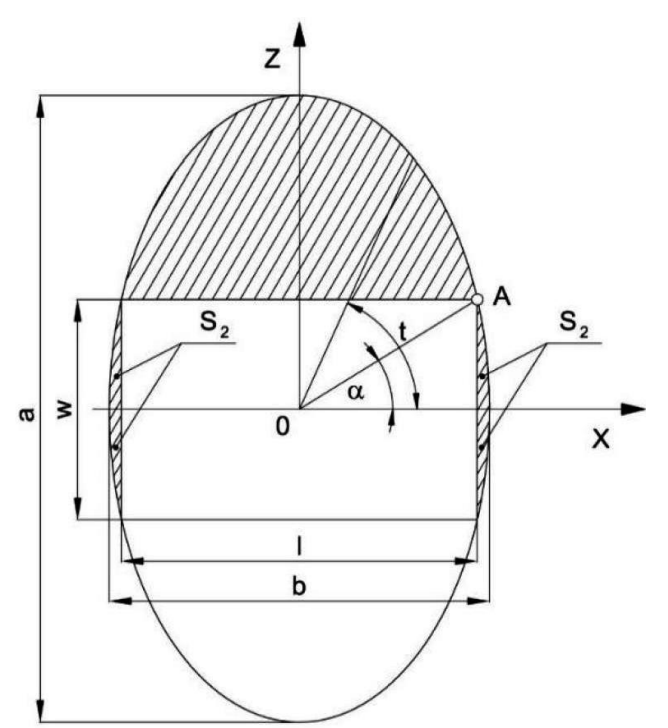

Fig. 1 Stress-relieved zone around the void (working) in the rock mass (Strzałkowski, 2015).

formation was formulated based on the law of conservation of mass. Analytical sinkhole prediction methods have been developed in Poland (Chudek et al., 1998).

Within this paper, the authors have characterized the problems of predicting discontinuous surface deformations and provided a practical example of using the deterministic method.

\section{AN EXAMPLE OF ANALYSIS WITH THE USE OF THE DETERMINISTIC METHOD}

In the article written by Strzałkowski (2015), the method based on A. Sałustowicz's pressure arch theory (Sałustowicz, 1956) was used to develop a mathematical modelling sinkhole occurrence. The condition for the arch to form is the fulfilment of the condition: $\sigma_{x \max } \geq R_{r}$.

$\sigma_{\mathrm{x} \max }-$ maximal tensile stress in the heading roof in the $\mathrm{x}$ direction, $\mathrm{R}_{\mathrm{r}}$ - tensile strength of the rocks. Otherwise, the working remains in a stable state without supports.

The area of the $\mathrm{P}_{\mathrm{e}}$ stress-relieved zone in concern (crosshatched in Fig. 1) is:

$$
P_{e}=S_{1}-\frac{w l}{2}+2 \cdot S_{2}
$$

where:

$\mathrm{S}_{1}$ - area of the top half of the fracture zone in the shape of ellipse (stress-relieved zone), with a and b axes, $S_{1}=\frac{\pi a b}{8}$

w, 1 - height and width of the working

$S_{2}=\frac{1}{2} \int_{0}^{k}\left[\frac{b}{2} \cos t \cdot \frac{a}{2} \cos t-\frac{a}{2} \sin t \cdot \frac{b}{2}(-\sin t)\right] d t-\frac{w l}{8}=\frac{a b k-w l}{8}$

$\mathrm{k}$ - arc measure of the a angle, thus $\mathrm{k}=p a / 180^{\circ}$

$$
k=\frac{\pi}{180^{\circ}} \cdot \arctan \frac{w}{l}
$$

Thus:

$P_{e}=\frac{a b(\pi+2 k)-6 w l}{8}$

In the paper (Strzałkowski, 2015), two expressions have been determined:

$P_{1}=P_{e} \cdot k_{r}$

$P_{2}=P_{e}+w \cdot l$

where:

$\mathrm{k}_{\mathrm{r}}$ - coefficient of loosening of rocks

Two cases may be distinguished:

- $\quad$ if $P_{1}=P_{2}$, a self-backfilling of the void will occur and the rocks contained in the stress-relieved zone will fill it tightly,

- if $P_{1}<P_{2}$, a secondary void will be formed in the area of the top of the stress-relieved zone, with a volume resulting from the difference in the $\mathrm{P}_{2}-$ $\mathrm{P}_{1}$ areas. If the related stress-relieved zone will bottom border of the overburden, a sinkhole will be formed.

Based on the above reasoning, a computer program written by Strzałkowski in 2015 has been presented in (Strzałkowski, 2017). This programm was written by my son Jacek, not by me, so I would like to highlight that.

\section{CASE STUDY OF A SINKHOLE OCCURRENCE}

In 2010, in the area of a parking lot, a sinkhole was formed with the dimensions of $6 \times 5 \mathrm{~m}$ in horizontal projection and the depth of approx. $2.5 \mathrm{~m}$, over the Main Hereditary Key Adit in Chorzów. Based on the paper presented by Duży et al. (2015) and conference article written by Wiśniewski (2015) it has been determined that the floor of the adit in the location of the sinkhole is at the depth of $44.4 \mathrm{~m}$. Based on the papers, the probable dimensions of the cross section of the adit have been established: the height of $3 \mathrm{~m}$ and the width of $3.7 \mathrm{~m}$. The structure of the rock mass has been established based on the lithological profile of the Dill shaft present at a distance of approx. $180 \mathrm{~m}$ from the sinkhole location. The lithological profile along with the cross section of the heading has been presented in Figure 2.

The overburden consists of sand and loam. The carboniferous layers have been built by sandstone, clay slate and a coal seam.

In the calculations, the assumptions based on the paper (Duży et al., 2015) presented in Table 1 have been used.

The course of the adit was marked at the fragment of the surface map (Fig. 3). In the figure, also the location of the sinkhole was marked. Figure 4 presents a photograph - a general view of the sinkhole.

The application of the computer programme described by Strzałkowski (2017), allowed to achieve calculation results presented in Figure 5. The primary void (the adit) as well as the secondary voids occurring towards the surface has been presented. The stress-relieved zone formed around the void has reached the loose overburden. Thus, based on 


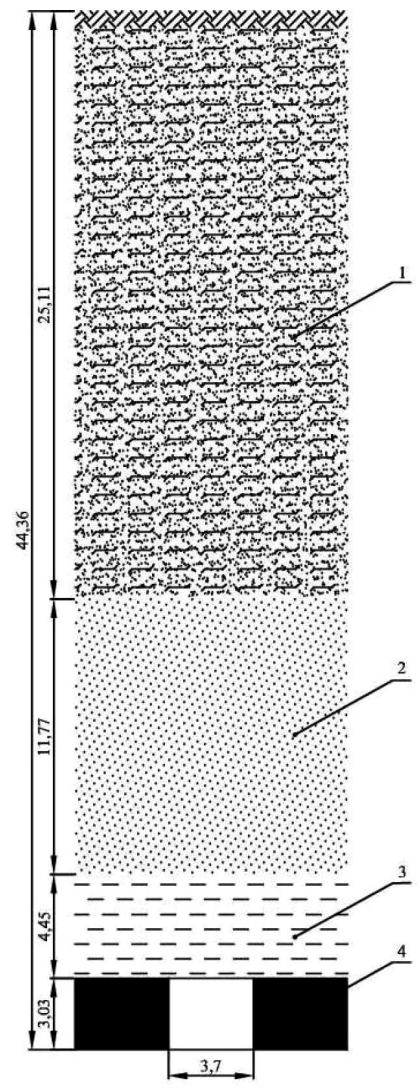

Fig. 2 Lithological profile in the area of the sinkhole 1 - sand with loam, 2 - sandstone, 3 - clay slate, 4 - coal.

Table 1 Physical properties of the rock mass strata assumed in the calculations.

\begin{tabular}{lrlll}
\hline Stratum & $\mathbf{m}$ & $\begin{array}{c}\mathbf{R}_{\mathbf{r}} \\
{[\mathbf{M P a}]}\end{array}$ & $\begin{array}{c}\mathbf{g} \\
{\left[\mathbf{M N} / \mathbf{m}^{3}\right]}\end{array}$ & $\mathbf{k}_{\mathbf{r}}$ \\
\hline Sandy loam & 25.11 & 0.01 & 0.027 & 1.00 \\
Sandstone & 11.77 & 0.40 & 0.025 & 1.20 \\
Clay slate & 4.45 & 0.15 & 0.025 & 1.15 \\
Coal seam & 3.03 & 0.30 & 0.014 & 1.20 \\
\hline
\end{tabular}

where: $\mathrm{m}$ - thickness of the stratum, $\mathrm{R}_{\mathrm{r}}$ - tensile strength, $\mathrm{g}$ - bulk density, $\mathrm{k}_{\mathrm{r}}$ - rock loosening coefficient. the calculation results, a sinkhole was formed at the surface.

\section{CONCLUSIONS}

Discontinuous deformations, especially sinkholes, are formed over shallow working excavation long after the underground exploitation of deposits is completed, causing a hazard to general safety. A considerable number of sinkholes are formed above shallow headings due to the loss of bearing capacity of old wooden supports. Because of the above, the problem of forecasting the formation of sinkholes gains significance. The presented study case - another example of using the method based on A. Sałustowicz's pressure arch theory for providing an ex post prognosis indicates its practical usability. The generated predictions constitute a basis for engineers and managers making decisions related to landscaping of post mining areas.

\section{REFERENCES}

Baryakh, A.A. and Fedoseev, A.K.: 2011, Sinkhole formation mechanism. J. Min. Sci., 47, 4, 404-412.

Brinkmann, R., Parise, M. and Dye, D.: 2008, Sinkhole distribution in a rapidly developing urban environment: Hillsborough County, Tampa Bay, Florida. Eng. Geol., 99, 3-4. June, 169-184. DOI: $10.1016 /$ j.enggeo.2007.11.020

Chudek, M., Janusz, W. and Zych, J.: 1998, Study concerning the development and prediction of discontinuous deformations caused by underground exploitation. Scientific Journal of Silesian University of Technology, Mining series, 141, Gliwice, 161 pp., (in Polish).

Doctor, K.Z., Doctor, D.H., Kronenfeld, B. et al.: 2008, Predicting sinkhole susceptibility in Frederick Valley, Maryland using geographically weighted regression. 11th Multidisciplinary Conference on Sinkholes and the Engineering and Environmental Impacts of Karst 2008. September 22-26, 2008 Tallahassee, Florida, United States.

Duży, S. et al.: 2015, Conducting tests and geophysical analyses of the structure of rock mass in the direct vicinity of the headings of the Main Hereditary Key Adit, locating selected liquidated headings and designing the protection of the workings of the Main Hereditary Key Adit along with the author's

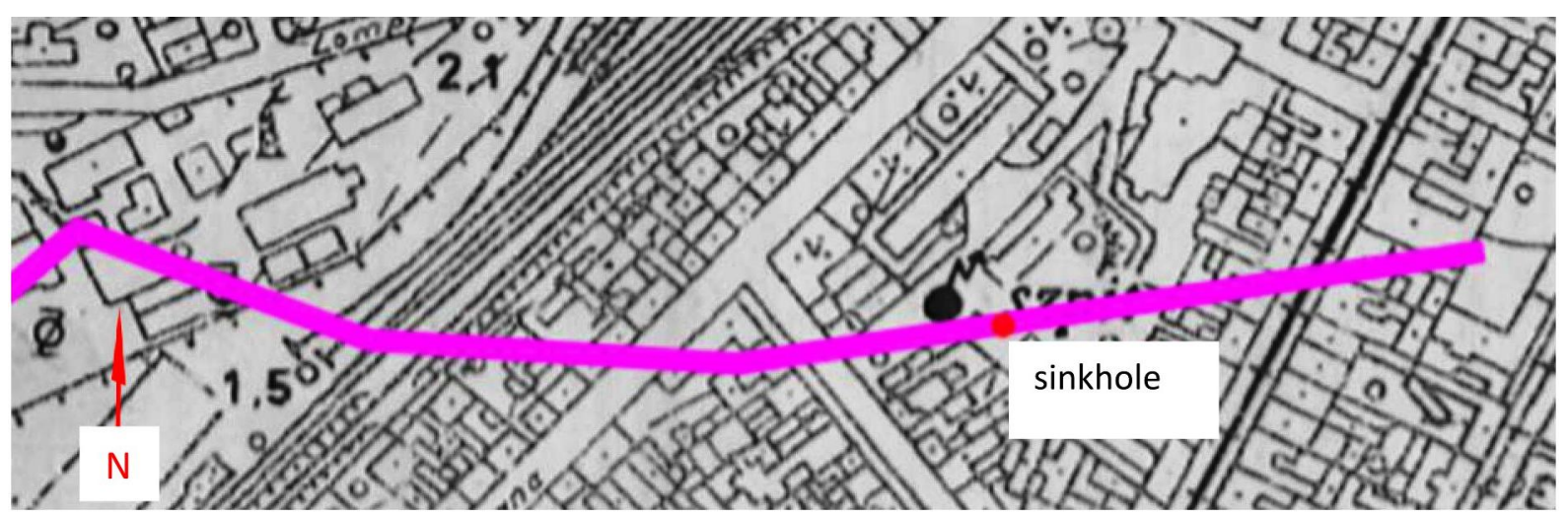

Fig. 3 Course of the adit and the location of the sinkhole marked on the surface map. Scale 1:5000 


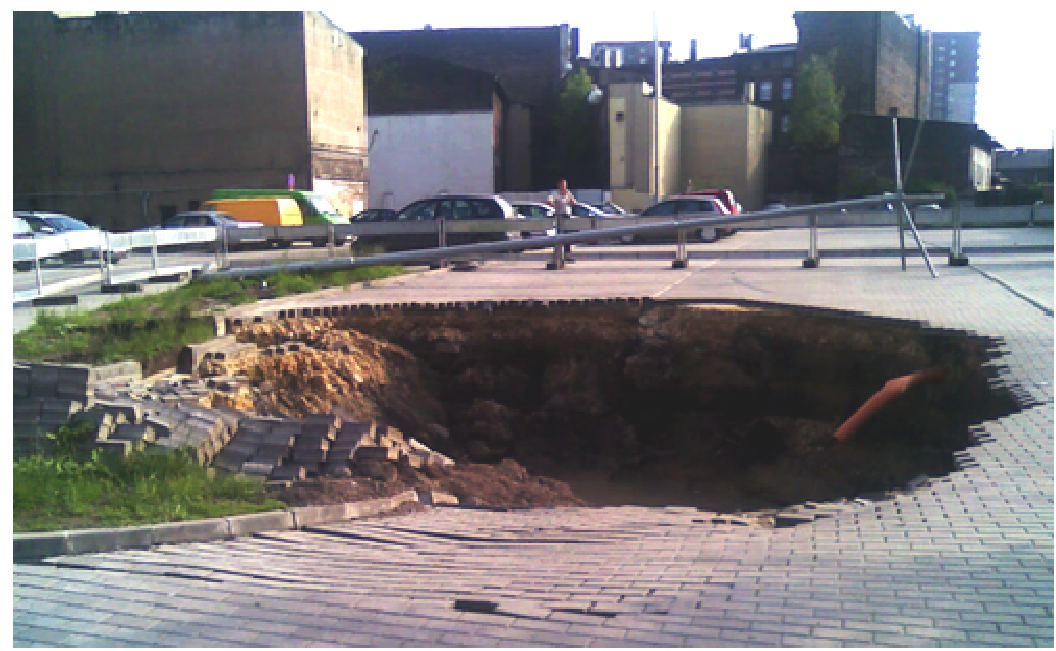

Fig. 4 General view of the sinkhole (photo by K. Kokowski).

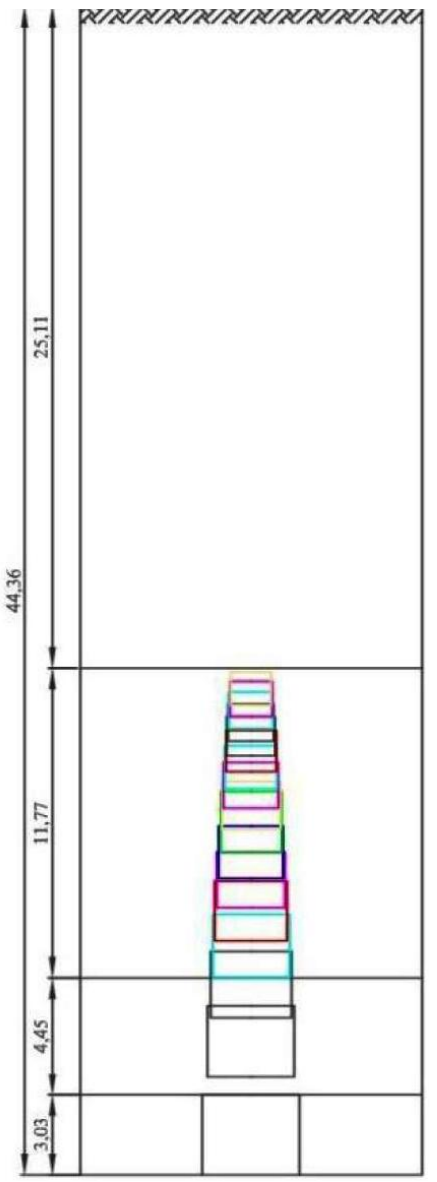

Fig. 5 Calculation results presenting subsequent voids, including the final one, in which the cracking zone reached the overburden layer.

supervision. Research work of the Department of Geomechanics, Underground Construction and Surface Protection Management of the Faculty of Mining and Geology of Silesian University of Technology. Paper not published. Gliwice, (in Polish).

Dżegniuk, B., Piwowarski, W. and Pielok, J.: 1994, Differential equations with singularities in the analysis of non-stationary processes of rock mass mechanics. Scientific Journals of the Silesian University of
Technology, Mining series, 221, Gliwice, 165-178, (in Polish).

Hunter, J.: 2015, Old mines and new sinkholes along the Hucklow Edge vein, Derbyshire. Mercian Geologist, $18,4,213-226$.

Kaufmann, G.: 2014, Geophysical mapping of solution and collapse sinkholes. J. Appl. Geophys., 111, 271-288. DOI: $10.1016 /$ j.jappgeo.2014.10.011

Kratzsch, H.: 1983, Mining subsidence engineering. Springer-Verlag, Berlin, Heidelberg, New York, 543 pp.

Malinowska, A.A. and Matonóg, A.: 2017, Sinkhole hazard mapping with the use of spatial analysis and analytical hierarchy process in the light of mining-geological factors. Acta Geodyn. Geomater., 14, 2 (186), 159172. DOI: $10.13168 /$ AGG.2016.0037

Reddish, D.J. and Whittaker, B.N.: 1989, Subsidence: Occurrence, prediction and control. Developments in Geotechnical Engineering, 56, 528 pp.

Sałustowicz, A.: 1956, Outline of rock mass mechanics. Śląsk Publishing House, Katowice, 192 pp., (in Polish).

Soriano, M.A., Simon, J.L., Gracia, J. and Salvador, T.: 1994, Alluvial sinkholes over gypsum in the Ebro basin (Spain): genesis and environmental impact. Hydrog. Sci., 39, 3, 257-268. DOI: $10.1080 / 02626669409492742$

Strzałkowski, P.: 2010, Outline of protection of mining areas. The Silesian Technical University, Gliwice, (in Polish).

Strzałkowski, P.: 2015, Mathematical model of forecasting the formation of sinkhole using Salustowicz's theory. Arch. Min. Sci., 60, 1, 63-71. DOI: $10.1515 / \mathrm{amsc}-2015-0005$

Strzałkowski, P.: 2017, Proposal of predicting formation of sinkholes with an exemplary application. J. Min. Sci., 53, 1, 53-58. DOI: 10.1134/S1062739117011835

Wiśniewski, L.: 2015, Main Hereditary Key Adit as a historic European cultural heritage object, (in Polish). Avalable at: www.gwarkowie.pl/pliki/glownakluczowa-sztolnia-dziedziczna-917.pdf

Xiao, H., Kim, Y.J., Nam, B.H. and Wang, D.: 2016, Investigation of the impacts of local-scale hydrogeologic conditions on sinkhole occurrence in East-Central Florida, USA. Environ. Earth Sci., 75, 18. 1274. 